\title{
Acquired localised hypertrichosis in a Chinese child after cast immobilisation
}

\author{
MW Yuen *, Loretta KP Lai, PF Chan, David VK Chao
}

\begin{abstract}
A B S T R A C T
Hypertrichosis refers to excessive hair growth that is independent of any androgen effect. Hypertrichosis could be congenital or acquired, localised or generalised. The phenomenon of acquired localised hypertrichosis following cast application for a fracture is well known to orthopaedic surgeons, but is rarely encountered by primary care physicians. We describe a 28-month-old Chinese boy who had fracture of right leg as a result of an injury. He had a cast applied by an orthopaedic surgeon as treatment. On removal of the cast 6 weeks later, he was noticed to have significant hair growth on his right leg compared with the left leg. The patient was reassessed 3 months after removal of the cast. The hypertrichosis resolved completely with time. This patient was one of the youngest among the
\end{abstract}

reported cases of acquired localised hypertrichosis after cast application. We illustrate the significance of management of post-cast-acquired localised hypertrichosis in the primary care setting.
Hong Kong Med J 2015;21:369-71
DOI: $10.12809 / \mathrm{hkmj} 144414$
MW Yuen *, MB, ChB
LKP Lai, MFM, FHKAM (Family Medicine)
PF Chan, MOM, FHKAM (Family Medicine)
DVK Chao, FRCGP, FHKAM (Family Medicine)
Department of Family Medicine and Primary Health Care, Kowloon East
Cluster, Hospital Authority, Hong Kong
* Corresponding author: ymw847@ha.org.hk

\section{Introduction}

Hair growth pattern in humans depends on age, sex, and race. ${ }^{1}$ Hypertrichosis refers to excessive hair growth that is inappropriate for a patient after consideration of the normal variation of an individual's reference group. ${ }^{2}$ Hypertrichosis is different from 'hirsutism', which is caused by excessive androgen-sensitive hair growth. ${ }^{1}$ Hypertrichosis can be categorised into congenital versus acquired and generalised versus localised, and it may cause considerable psychological stress. ${ }^{3}$ Acquired localised hypertrichosis (ALH) following a fracture or cast application has been reported in different countries. In this case report, a Chinese boy with localised hypertrichosis in the right leg after application of a cast following right leg fracture is described. To the best of our knowledge, this patient represents one of the youngest reported cases.

\section{Case report}

In January 2014, a 28-month-old Chinese boy presented to the general out-patient clinic at Tseung Kwan O Hospital in Hong Kong with limping gait after removal of a cast applied for right leg fracture. During the consultation, the child was observed to have excessive hair growth on his right leg. He had a history of right leg fracture 6 weeks previously after he accidentally fell from a height of $1.5 \mathrm{~m}$. He had consulted a private orthopaedic surgeon and a cast was applied for 6 weeks. After removal of the cast, he was noticed to have a lot of new hair growth on his right leg. There was no increased hair growth over the left leg or other body parts. There was no history of systemic or topical medication use before the onset of increased hair growth. The mother was concerned about whether any treatment was needed for the excessive hair growth.

On physical examination, there was significantly increased thick dark hair growth over the anterior and lateral parts of the right leg previously covered by the cast (Fig 1). There was no other skin change. The new hair growth caused no skin symptoms to the child. The child walked with a mild limping gait, but there was no limb deformity, muscle wasting, or bony tenderness.

The patient was diagnosed with ALH due to cast application. The patient's mother was reassured about the benign, transient, and self-limiting nature of the condition. His limping gait was treated with physiotherapy. He was followed up at 3 months, when his gait had become normal and there was spontaneous complete resolution of the localised hypertrichosis (Fig 2).

\section{Discussion}

There are many causes of ALH such as chronic irritation (eg skin overlying areas of thrombophlebitis 


\section{一名華籍兒童接受石亳固定治療後出現 局部性多毛症}

袁明慧、黎潔萍、陳鵬飛、周偉強

多毛症是指在不受任何雄激素影響下出現毛髮過度生長的情況。多毛 症可分為先天或後天, 以及局限性或全身性。病人在接受骨折石膏固 定治療後出現局部多毛症對於骨科醫生來説是一個已知的現象, 但基 層醫生卻很少遇到。本文報告一名28個月大的兒童因右小腿受傷骨折 須接受骨科醫生的石亳固定治療。6 個星期後替病人拆石膏時發現他 右小腿上的毛髮明顯比左腿多。病人拆石膏後 3 個月再接受評估, 多 毛症完全消失。這名病人是類似病例報告中最年輕的一位。本文説明 在基層醫護層面上, 為病人治理因石膏固定治療而出現局部多毛症的 意義 or chronic osteomyelitis), friction (eg lichen simplex chronicus, insect bites, atopic eczema), or inflammation (eg chemical-induced dermatitis, ultraviolet irradiation, vaccination sites). ${ }^{2}$ It is not uncommon to find ALH following prolonged cast or splint application for various orthopaedic conditions. A Turkish study involving 117 patients showed that post-cast hypertrichosis might occur in up to one third of patients. ${ }^{4}$ The study showed that there was no sex predisposition, but the frequency peaked in the adolescent age-group. ${ }^{4}$ Post-cast ALH has been reported in paediatric and young adult patients in various countries from 1989 to 2013, but the prevalence in local Chinese patients is unknown. ${ }^{5-11}$ Complete resolution of hypertrichosis was noted at around 3 to 9 months after removal of the cast or splint.

One of the major mechanisms of hypertrichosis is conversion of vellus to terminal hair. Vellus hair is fine, non-pigmented, and produced by hair follicles located in the dermis. Vellus hair develops on almost all parts of the body, and its growth is not affected by hormones. Terminal hair is thick, pigmented, and produced by large hair follicles located in the subcutis. Terminal hair is found on sites where hair growth is affected by hormones, eg scalp, beard, axillae, and pubic area. ${ }^{12}$ Vellus-to-terminal switch on body sites that usually do not have terminal hairs will cause hypertrichosis. The underlying mechanism of this vellus-to-terminal switch is still poorly understood. ${ }^{13}$

Another major mechanism of hypertrichosis involves change in the hair growth cycle. Hair follicles undergo lifelong cyclic transformation in three stages: anagen, the active growth phase; catagen, the apoptosis-driven phase; and telogen, the resting phase followed by hair shedding. ${ }^{12}$ Hypertrichosis results when the hair follicles stay longer than usual in the anagen phase. Similar to vellus-to-terminal switch, control of the hair growth cycle is still not well understood. ${ }^{1}$

The pathogenesis of post-cast hypertrichosis after fracture is not well-established and different hypotheses have been postulated. Some authors suggested that prolonged cast application provides an occlusive, moist, and warm environment which, together with irritation caused by friction, promotes hair growth. ${ }^{11}$ Some authors, however, believe that the increase in regional blood flow to the bone following fracture provides abundant oxygen and nutrients that prolong the anagen phase of hair growth, resulting in transient hypertrichosis. ${ }^{6}$ This hypothesis is supported by the speculation that hypertrichosis has also been observed after splint application that does not occlude the injured area, suggesting that the fracture-healing process rather than the cast-occlusion effect led to hypertrichosis. ${ }^{10}$ Other hypotheses on the pathogenesis of ALH 
include transient cutaneous hyperaemia stimulating the hair follicles ${ }^{5}$ and reflex sympathetic dystrophy induced by immobilisation causing vasodilatation of the affected area and stimulating hair growth. ${ }^{7}$

Post-cast ALH is more commonly observed in children and young adults. ${ }^{4}$ This could be explained by age-related changes in hair growth. With ageing, the activity of the hair follicles declines and the hair growth rate decreases. Since older adult patients have a shorter anagen period of the hair growth cycle, ALH is less frequently observed in this agegroup. Children and young adults do not have this unfavourable effect of the ageing process on hair growth to cancel stimulation of hair follicles after cast application, and therefore post-cast ALH is more commonly seen in this younger age-group.

Cases of ALH following fracture or cast application have been described by orthopaedic surgeons and dermatologists, but not in the primary care setting. Nonetheless, such cases may be encountered in primary care. Therefore, family physicians should be aware of the diagnosis and management of the condition and its implications for psychosocial consequences, since hypertrichosis may cause considerable emotional stress to patients due to the unsightly cosmetic appearance. ${ }^{10}$ We should address any psychological distress brought about by hypertrichosis and reassure patients and their parents about the benign and transient nature of ALH after cast application. In most cases, the abnormal hair growth will disappear within 6 months, as in this patient, and further investigation or intervention is not indicated. If, however, hypertrichosis causes cosmetic or psychological problems for the patient, hair removal-for example, by shaving or other mechanical methods-could be considered. ${ }^{2}$

\section{References}

1. Bertolino A, Freedberg I. Hair. In: Fitzpatrick TB, Eisen AZ, Wolff K, Freedberg IM, Austen KF, editors. Dermatology in general medicine. New York: McGraw-Hill; 1993: 671-96.

2. Wendelin DS, Pope DN, Mallory SB. Hypertrichosis. J Am Acad Dermatol 2003;48:161-79.

3. Vashi RA, Mancini AJ, Paller AS. Primary generalized and localized hypertrichosis in children. Arch Dermatol 2001;137:877-84.

4. Akoglu G, Emre S, Metin A, Bozkurt M. High frequency of hypertrichosis after cast application. Dermatology 2012;225:70-4.

5. Leung AK, Kiefer GN. Localized acquired hypertrichosis associated with fracture and cast application. J Natl Med Assoc 1989;81:65-7.

6. Kara A, Kanra G, Alanay Y. Localized acquired hypertrichosis following cast application. Pediatr Dermatol 2001;18:57-9.

7. Rathi SK. Localized acquired hypertrichosis following cast application. Indian J Dermatol Venereol Leprol 2007;73:367.

8. Leung AK, Wong AS. Localized acquired hypertrichosis associated with the application of a splint. Case Rep Pediatr 2012;2012:592092.

9. Ma HJ, Yang Y, Ma HY, Jia CY, Li TH. Acquired localized hypertrichosis induced by internal fixation and plaster cast application. Ann Dermatol 2013;25:365-7.

10. Harper MC. Localized acquired hypertrichosis associated with fractures of the arm in young females. A report of two cases. Orthopedics 1986;9:73-4.

11. Chang $\mathrm{CH}$, Cohen PR. Ipsilateral post-cast hypertrichosis and dyshidrotic dermatitis. Arch Phys Med Rehabil 1995;76:97-100.

12. Wolff K, Johnson RA, Saavedra AP. Disorders of hair follicles and related disorders. In: Fitzpatrick's color atlas and synopsis of clinical dermatology. New York: McGrawHill; 2013: 760-89.

13. Stenn KS, Paus R. Controls of hair follicle cycling. Physiol Rev 2001;81:449-94. 